ORIGINAL RESEARCHARTICLE

\title{
Value Creation and Value Appropriation in Innovative Coopetition Projects
}

\author{
Paul Chiambaretto "* , Jonathan Maurice², and Marc Willinger ${ }^{3}$ \\ IMRM-Montpellier Business School and i3-CRG, Ecole Polytechnique, CNRS, Montpellier, France; ${ }^{2}$ TSM-Research, \\ Toulouse Capitole University, CNRS, France; ${ }^{3}$ CEE-M, University of Montpellier, CNRS, INRA, SupAgro, Montpellier, \\ France
}

\begin{abstract}
This article provides a formal model of the value creation-appropriation dilemma in coopetition for innovation, that is, alliances among competing firms. The model determines the levels of cooperation that maximize the profit of each firm in an innovative coopetition agreement regardless of the number of firms and their respective budget endowments dedicated to the coopetitive project. We answer the following questions: within an innovative coopetition agreement, will the partners cooperate more or less when their budget endowments change? What is the impact on profit? When is it profitable to accept a new partner into the agreement? What happens to the remaining firms when a partner withdraws from the agreement? We show that when the coopetitive budget of the focal firm increases, the focal firm allocates a larger part of this budget to value creation activities and increases its profit. In contrast, when a partnering firm increases its coopetitive budget, the focal firm reduces its budget for value creation activities to maintain a sufficient budget for value appropriation activities. We also show that the addition of a competitor with a large coopetitive budget to the innovative coopetition agreement decreases the cooperation of the focal firm but increases the profit of the initial partnering firms. In contrast, the exit of a partnering firm with a large coopetitive budget from the agreement intensifies the cooperation among the remaining firms but reduces their profit.
\end{abstract}

Keywords: Coopetition; Value creation; Value appropriation; Innovative coopetition projects; Game theory

Handling Editor: Simon Porcher. Received: 19 February 2019; Accepted: 9 December 20 I9; Published: 2 June 2020

ncreasingly more firms rely on alliances between competitors to accelerate their development and foster innovation. Because these alliances present several particularities, a specific stream of literature has emerged around the concept of 'coopetition' (Brandenburger \& Nalebuff, 1996; Bengtsson \& Kock, 2000; Fernandez, Chiambaretto, Le Roy, \& Czakon, 20 I 8; Gnyawali \& Park, 201 I). Coopetition can be defined as a paradoxical situation in which firms compete in some activities, markets, or products but simultaneously cooperate regarding other activities. Coopetition is supposed to generate superior performance for the partnering firms as it combines the benefits of cooperation and competition (Ritala, 2012). However, coopetition also generates strong tensions between the participating firms (Fernandez, Le Roy, \& Gnyawali, 20 I 4;Tidström, 20 I4), which are mainly driven by the conflict between generating shared benefits and capturing private benefits (Ritala \& Hurmelinna-Laukkanen, 2018; Ritala \& Tidström, 2014).
Nevertheless, several scholars have argued that instead of attempting to reduce these tensions, firms must accept and manage them because their outcomes can be highly beneficial if these tensions are managed properly (Bengtsson, Raza-Ullah, \& Vanyushyn, 2016; Le Roy, Fernandez, \& Chiambaretto, 20l8; Le Roy \& Czakon, 2016).

The ability to manage coopetition implies that firms can find the correct balance between value creation and value appropriation strategies (Gnyawali \& Ryan Charleton, 2018; Park, Srivastava, \& Gnyawali, 2014). Although the claim that cooperative and competitive behaviors should be balanced is often made, few studies have analyzed in detail the nature and specifics of this balance. The existing contributions analyzing this balance remain mainly qualitative (Gnyawali \& Park, 2011; Ritala \& Tidström, 20 I4), or when quantitative assessments are made, they are done at the firm level and not at the coopetitive agreement level (Park et al., 2014). Moreover, despite

*Corresponding author: Paul Chiambaretto, Email: p.chiambaretto@montpellier-bs.com 
several calls for further analysis of the value creation-appropriation tension (Bengtsson \& Kock, 20l4; Chou \& Zolkiewski, 20 I 8; Ritala \& Hurmelinna-Laukkanen, 20 I 8; Ritala \& Tidström, 2014), little academic attention has been devoted to the details of the budget allocation between cooperation and competition.

Our aim is therefore to provide a theoretical framework that allows a discussion and analysis of the determinants of the balance between value creation and value appropriation within innovative coopetition projects. To do this, we develop a formal model based on a game-theoretical approach. We focus on allocative decisions of partners in a coopetitive agreement by modeling each partnering firm's choice as a decision about how to allocate a given amount of their budget between a common creative activity and a private appropriation activity. That is, we focus on budget allocations that are conditional on being a member of the coopetitive agreement, and we do not consider a firm's decision to enter or leave a coopetitive agreement. We frame the budget allocation strategies as a standard one-stage noncooperative game. Each firm chooses an allocation that is a best response to the budget allocation chosen by the other partners.

Our research differs from previous contributions regarding the value creation/appropriation dilemma in coopetition along several dimensions. First, contrary to previous articles that provide a qualitative assessment of the balance between cooperative and competitive behaviors, our game-theoretical approach allows us to capture the strategic uncertainty that surrounds managers' decisions in an innovative coopetition agreement. By doing this, we identify the equilibrium allocation of the budget for each participant involved in the agreement between value creation activities and value appropriation activities. Second, while previous game-theory models were decomposing such agreements in two phases as a two-stage game (compete-then-cooperate or cooperate-then-compete), we adopt a single-stage approach to take into account the specificities stemming from the simultaneity of competition and cooperation in coopetition. By doing so, we provide a stronger analysis of the dilemma between value creation and appropriation by putting the tension between these two objectives in the core of the analysis. Third, contrary to previous research that assumed that value creation and value appropriation behaviors were independent, we adopt a perspective in which the partnering firms have a limited budget such that allocation decisions made for value creation are made at the expense of value appropriation. Fourth, consistent with a recent stream of research inviting researchers to investigate coopetitive agreements involving more than two partners, our modeling allows us to analyze the value creation/appropriation dilemma in settings involving more than two partners with different sizes or budgets. Finally, in contrast to previous articles identifying a specific balance in a given situation, our approach allows us to realize some comparative statics and answer various questions, such as the following: will the focal firm cooperate more or less when its budget dedicated to coopetitive activities increases? What is the impact of such a change on its profit? What is the impact of an increase in the coopetitive budget of a partner firm on the focal firm's cooperativeness and profit? To what extent is it profitable for firms belonging to an established coopetition agreement to accept a new partner into the agreement? What are the consequences for a firm that remains in the agreement if a partner withdraws from it?

We show that there is a unique Nash equilibrium budget allocation for each firm, which depends on the number of firms and their dedicated budgets. In addition, we show that the Nash budget allocations and profits evolve according to some key factors. When the focal firm's dedicated budget (to the coopetitive project) increases, it allocates a larger fraction of it to value creation activities and increases its profit. By contrast, when a partnering firm increases its budget, the focal firm reduces its investment in value creation activities to increase its appropriation capacity. As the partner increases its budget dedicated to coopetition, the focal firm sees its Nash profit increase. Finally, we show that the entry of a new competitor into an existing coopetitive agreement reduces the focal firm's investment in the coopetitive project and increases the profit for the initial partners only if the incomer's coopetitive budget is sufficiently large. Symmetrically, the exit of a standing partner is profitable for the remaining firms only if the exiting partner has a relatively small coopetitive budget.

Our research contributes to the growing literature on coopetition and innovation by offering a formal model that allows us to study the incentives for competing firms to cooperate with one another to create common appropriable value. More precisely, we provide a theoretical analysis of the value creation/appropriation dilemma in a simultaneous cooperation-competition game between heterogeneous firms. To our knowledge, this paper is the first to develop a formal analysis of this value creation/value appropriation dilemma that offers clear theoretical predictions for firms' coopetitive strategies in a one-stage game. Our very generic model allows us not only to characterize the equilibrium for any fixed number of firms but also to study how it evolves when the structure of the agreement changes.

\section{Theoretical background}

\section{Combining cooperative and competitive behaviors in coopetition strategies}

As a growing number of firms cooperate with competitors (Fernandez et al., 20। 8), the concept of coopetition has been developed to analyze and understand the specificities of these strategies (Brandenburger \& Nalebuff, 1996). 
Accordingly, coopetition can be defined as "a paradoxical relationship between two or more actors simultaneously involved in cooperative and competitive interactions, regardless of whether their relationship is horizontal or vertical" (Bengtsson \& Kock, 2014, p. 182). Because it combines the benefits of cooperative and competitive behaviors (Bengtsson \& Kock, 2000; Lado, Boyd, \& Hanlon, 1997), coopetition is expected to yield superior performance compared to other relational modes. Although several contributions indeed find a positive impact of coopetition on innovation performance (Bouncken \& Kraus, 20|3), market performance (Robert, Chiambaretto, Mira, \& Le Roy, 20 I 8), or stock-market performance (Wu, Luo, Slotegraaf, \& Aspara, 2015), some recent reviews have underlined that coopetition has a mixed impact in terms of performance, either from an innovation (Gast, Hora, Bouncken, \& Kraus, 2018) or from a market performance standpoint (Ritala, 20 8).

A possible explanation of these mixed results comes from the presence of multiple coopetitive tensions felt at different levels (Fernandez et al., 2014; Tidström, 2014). Because the partnering firms are competitors, they have to address contradictory and paradoxical incentives that force them to sufficiently cooperate to create value while competing to capture enough value (Fernandez \& Chiambaretto, 20l6). To avoid self-destructive behaviors, several contributions have noted that coopetitors need to manage these tensions if they want to make it a successful strategy (Le Roy \& Czakon, 2016; Le Roy et al., 20।8). In this vein, Park et al. (2014) show that the firms that can find the right balance between their collaborative and competitive efforts tend to exhibit higher innovation performance.

\section{Specificities of value creation and value appropriation in coopetition}

In their seminal contribution, in addition to introducing the term 'coopetition', Brandenburger and Nalebuff (1996) underline the tensions related to the cooperative dimension of value creation and the competitive dimension of value appropriation. By using the metaphor of a cake, they explain that the cooperative side of coopetition increases the size of the cake, whereas the competitive side increases the size of the slice. That is, tensions between cooperation and competition are driven by the conflict between generating shared benefits and capturing private benefits (Ritala \& Hurmelinna-Laukkanen, 20 18; Ritala \& Tidström, 20l4). It is interesting to note that even if the cooperative side of coopetition generates common benefits for the partnering firms, the allocation of the efforts between value creation and value appropriation activities is not made in concert with the coopetitors (Ritala \& HurmelinnaLaukkanen, 2018). Consequently, each firm has to find the optimal budget allocation to maximize its profit (at the expense of the other partnering firms). By building on Lavie (2007), we define value creation as the value generated by the relationships with partners as they collectively pursue shared objectives. In contrast, value appropriation determines the relative share of the relational rents that the focal firm can appropriate.

Even if partners must also decide how they will share and appropriate the relational rent generated by the cooperation in alliances between noncompetitors (Adegbesan \& Higgins, $20 \mathrm{II}$ ) under coopetition, the value appropriation patterns are very different. The main specificity comes from the simultaneity of cooperative and competitive behaviors (Gnyawali \& Ryan Charleton, 20 18). Simultaneity can be understood in two ways. First, simultaneity can be understood as the fact that two firms cooperate in some markets, while they remain at the same time competitors in other markets. For instance, Le Roy and Fernandez (2015) emphasize how Astrium (Airbus Group) and Thales fully cooperated on a satellite program (Yahsat) while remaining in competition for other satellite markets. In this situation, each parent firm has to make a decision on the amount of budget (and engineer time) to allocate to the common project on the one hand and to the competing activity on the other hand. In parallel, simultaneity can be understood as the situation in which two firms cooperate on a joint product while developing, at the same time, unique knowledge, features, or competencies that will be used to improve the joint product so that they will have a larger market share than their coopetitor. For example, Gnyawali and Park (20II) explain how Sony and Samsung allocated teams to develop in cooperation a new Liquid Crystal Display (LCD) technology for televisions while having in parallel other teams that worked on specific features that would allow Sony to develop a better final LCD product than Samsung. In this case, a single decision is made at the beginning of the product development stage to determine how to optimally allocate the budget (or the team members) between the cooperative and competitive activities.

Regardless of the simultaneity approach adopted, several contributions that have focused on the value creation/appropriation dilemma have concluded that cooperative and competitive behaviors must be balanced (Bengtsson et al., 2016; Gnyawali \& Ryan Charleton, 2018; Le Roy et al., 2018; Park et al., 20 I 4; Ritala \& Hurmelinna-Laukkanen, 201 8; Ritala \& Tidström, 2014). Most of these papers are theoretical or qualitative contributions such that they define balance as "evenness between competition and cooperation" (Gnyawali \& Ryan Charleton, 2018, p. 2522). This concept of balance is quite blurry and yields general recommendations that state that partners must share resources and knowledge for the success of the common project while keeping sufficient resources for themselves to remain able to differentiate their offer from their competitors' offer in other projects. In that 
vein, Gnyawali and Ryan Charleton (2018, p. 2526) conclude that "a firm with more intent for firm value creation may prevent the joint pie from reaching its full potential, while pursuit of joint value creation may similarly hinder firm benefits."

To the best of our knowledge, the only quantitative contribution addressing this question of balance in coopetitive agreements is a study conducted by Park et al. (2014). The authors of this study first argue that "balance helps to maintain and control the relationship and at the same time increases the chances of realizing gains provided by both competition and collaboration" (p. 2/3). Accordingly, they expect firms that have a balanced behavior to present higher performance levels. Using the Securities Data Company (SDC) Platinum database, they show that firms that adopt a balanced coopetition strategy (with simultaneously a high degree of competition and a high degree of cooperation) tend to have a superior innovation performance. However, their measure of "balance" raises methodological questions as it is a mere multiplication of the competition and cooperation variables that are respectively measured as the degree of market commonality between the two firms (for the competition variable) and the number of repeated ties between the two firms (for the cooperation variable). Furthermore, Park et al. (2014)'s investigation is made at the firm level and not at the dyadic (or agreement) level so that they do not actually investigate the value creation and value appropriation behaviors within a given coopetition agreement.

Despite several calls for further analysis of the value creation-appropriation tension in coopetition (Bengtsson \& Kock, 2014; Chou \& Zolkiewski, 2018; Ritala \& HurmelinnaLaukkanen, 20।8; Ritala \& Tidström, 20।4), to the best of our knowledge, no study has investigated the details of the budget split between cooperation and competition within coopetition projects. In this research, we investigate how firms actually decide to allocate their budget to cooperative or competitive activities in coopetition projects. By doing so, contrary to previous contributions that provide either a qualitative or firmlevel assessment of the 'balance' firms need to reach, we aim at determining precisely the balance associated with each coopetitive agreement and observe how this balance evolves when key parameters change (number of partners involved, budget dedicated to the coopetitive project, etc.).

However, determining the optimal budget allocation between value creation and value appropriation activities is challenging and requires a specific modeling approach.'

\footnotetext{
I. In this article, we do not aim at investigating the trade-off between coopetitive and private activities (which would match with the first approach of simultaneity). Nevertheless, we provide some discussion regarding this situation in Appendix I.
}

\section{Modeling the trade-off between value creation and value appropriation in coopetition}

As explained by Ritala and Hurmelinna-Laukkanen (2009, 2018), some of the theoretical underpinnings of coopetition are rooted in the economics literature regarding conflict and appropriation, particularly contest games with endogenous prizes (see Garfinkel \& Skaperdas 2007 for a survey). This stream of literature, which is sometimes referred to as "Guns versus Butter," was initiated by Haavelmo (1954) and was mainly developed by the contributions of Hirshleifer (1989, 1991). The basic idea is that heterogeneously endowed agents must cooperate to produce goods jointly (e.g., butter) in a world of anarchy (without property rights); therefore, they must also privately build appropriation capacity (e.g., guns) to secure a share of the commonly produced goods. One of the striking results of this literature is the "paradox of power" (Hirshleifer, 1991), which equalizes the payoffs of asymmetric players. At equilibrium, resource heterogeneity leads poorly endowed agents to invest a larger share of their resources in producing guns rather than butter, while the well-endowed agents prefer the opposite allocation. The paradoxical result arises because the marginal return from appropriation is larger for poorly endowed players, whereas the marginal return from joint production is larger for the well-endowed. Nevertheless, modeling the trade-off between value creation and value appropriation in coopetition requires considering several specificities of coopetition strategies.

First, models based on sequential games fail to properly capture the resource allocation dilemma inherent to coopetitive agreements. Such models assume a sequential ordering of cooperation and competition: either an initial cooperative stage is followed by a competition stage (e.g., D'Aspremont \& Jacquemin, 1988; Grünfeld, 2003; Kamien \& Zang, 2000) or an initial competition stage is followed by a cooperative stage (Brandenburger \& Stuart, 2007; Gans \& Ryall, 2017; MacDonald \& Ryall, 2004; Panico, 2017). Let us refer to these two approaches as 'cooperate-then-compete' and 'compete-then-cooperate'. By breaking the coopetition dilemma into two stages, the dilemma actually becomes cleared. In the cooperate-then-compete literature, duopoly players choose their level of output in stage 2 (conditional on total R\&D investments in stage I), and then solve for their individually optimum level of R\&D investment in stage I. Solving the game by backward induction eliminates the dilemma. In the compete-then-cooperate literature, players built their appropriation capacity in stage I before bargaining in stage 2 to share a commonly created value. Again, by solving the game backwardly, the tension between appropriation capacity building (stage I) and value creation (stage 2) is eliminated. Our aim is to focus on the dilemma between value creation and appropriation by putting the tension between these two objectives in the core 
of the analysis. This tension between value creation and appropriation has been identified as the key issue of coopetitive agreements (Fernandez et al., 20 I 4; Gnyawali \& Ryan Charleton, 20 18; Ritala \& Tidstrom, 2014). To enhance the saliency of the tension between value creation and value appropriation, we need to rely on single-stage noncooperative game modeling.

Second, contrary to most models, which assume unlimited resources or budget, we assume that firms' budgets (or efforts) are limited. During strategic planning, firms decide how to allocate their limited resources among value creation and value appropriation activities. Therefore, both types of activities are interdependent. As explained by Gnyawali and Ryan Charleton (2018, p. 2526), "past a certain point, the finite nature of resources means that efforts to push joint value creation will occur at the expense of firm value creation and vice versa." Accordingly, our modeling will require firms to make a trade-off between value creation and value appropriation activities because of their finite budget.

Third, whereas most previous contributions considered partners of similar sizes or similar bargaining powers, we follow Panico's (2017) advice to allow for heterogeneous power positions of partners in an alliance. Recent articles have emphasized an increasing number of coopetitive agreements between firms of different sizes (Chiambaretto, Bengtsson, Fernandez., \& Näsholm, 2020; Hora, Gast, Kailer, Rey-Marti, \& Mas-Tur, 2018). We therefore consider in our model partner firms of different sizes (measured by the heterogeneity of their dedicated budgets for the coopetitive project).

Finally, in contrast to most contributions that investigate coopetition in dyadic agreements (Dorn, Schweiger, \& Albers, 2016), we follow the invitation by Ansari, Garud, and Kumaraswamy (2016) and Rouyre and Fernandez (2019) to study the case of multilateral or multipartner coopetition in which more than two competitors are involved in the agreement. Such configurations are particularly interesting as they reveal how the competitor's behavior changes according to their budget allocated to the coopetitive project and their own agenda.

\section{A formal model of coopetition for innovation}

\section{The setting}

We define an innovative coopetition agreement (a consortium or a joint venture) as a set of $K$ competing firms $(K \geq 2)$ that simultaneously cooperate on a joint project and compete. This agreement can either be a traditional dyadic coopetitive agreement $(K=2)$ or a setting of multipartner coopetition $(K \geq 3)$ that involves three or more competing firms. Each of the $K$ competing firms decides how to allocate its dedicated budget to the coopetitive project (the coopetitive budget hereafter) between value creation activities and value appropriation activities. We assume that value creation activities reflect cooperation, while value appropriation activities are related to competition.

Let us note that $n_{i}$ is the dedicated budget of firm $i$ to the coopetitive project. Although in real coopetitive projects, the resources dedicated to the coopetitive project have multiple dimensions, for example, money, time, skills, or technologies, for the purpose of our model, we assume that these dimensions can be converted into money and thus be considered as a budget. This implies that we abstract from the substitutability/ complementarity dimension of the resources by considering them as fungible. Considering $K$ firms, the set of coopetitive budgets available to all firms for the project is the set of K-uple vector $n=\left(n_{1}, n_{2}, \ldots, n_{k}\right)$. Let $N=\sum_{i=1}^{i=K} n_{i}$. We denote $\alpha_{i} \in[0,1]$, the share of firm i's budget allocated to value creation in the coopetitive project. $^{2}$ Firm $i$ therefore invests amount $\alpha_{i} n_{i}$ of its budget in the joint project for value creation and keeps $\left(I-\alpha_{i}\right) n_{i}$ for appropriation activities.

We assume that the total value created by the coopetitive project is equal to the sum of the investments in the cooperative activities. ${ }^{3}$ The total value of the project is $V\left(\alpha_{i}, \alpha_{-i}\right)$, which is a function of firm i's cooperative decision $\alpha_{i}$ and the other firms' cooperative decisions $\alpha_{-i}$ :

$$
V\left(\alpha_{i}, \alpha_{-i}\right)=\sum_{j=1}^{j=K} \alpha_{j} n_{j}
$$

We assume that $V\left(\alpha_{i}, \alpha_{-i}\right)$ is increasing in $\alpha_{i}$ and $\alpha_{-i}$. This specification implies that the partners' budgets are substitutable. $^{4}$

Regarding the appropriation behavior, we assume that the ability of firm $i$ to appropriate value from the joint project positively depends on two types of factors: exogenous factors and endogenous ones. Indeed, following Cohen and Levinthal (1990) or Ritala and Hurmelinna-Laukkanen (2013), we note that the absorptive capacity and the appropriation capability is the result of firm-specific exogenous factors and of endogenous factors

\footnotetext{
2. Strictly, the extreme cases for which a firm does not cooperate at all $\left(\alpha_{i}=0\right)$ or does not compete at all $\left(\alpha_{i}=1\right)$ cannot be considered as coopetition according to our definition which requires simultaneous cooperation and competition. However, for the sake of mathematical completeness, we also discuss these two extremes.

3. To account for empirical evidence that coopetition projects yield higher returns, a multiplicative factor can be added to our definition of the created value without changing the results of the paper.

4. More generally, our model assumes two types of substitutability: within-firm and across-partners. Within-firm substitutability refers to the allocation of a firm's budget between value creation and value appropriation, while across-partners substitutability refers to the interchangeability of the contributions to value creation.
} 
related to the specific agreement. The appropriation function in our model takes into account these two factors which we assume to be independent: (I) a firm-specific and exogenous organizational capacity in appropriating the value created collectively (this organizational capacity represents, for instance, unique knowledge, features, bargaining power, strategic importance, or specific competencies that will be used to improve the joint product and obtain a larger market share than partners); and (2) an agreement-specific endogenous capacity that depends positively on the amount of the firm i's budget that was not invested in value creation to be kept for the value appropriation. Referring to the theoretical literature, the firm-specific capacity is related to the compete-stage of the compete-then-cooperate approach, while the agreement-specific capacity is related to the compete-stage of the cooperate-then-compete approach.

From a mathematical standpoint, the exogenous appropriation capacity is expressed in relative terms to better capture that the focal firm's appropriation capacity depends upon the appropriation capacity of the other partners. Considering $K$ firms, the set of organizational appropriation characteristics of all firms is the K-uple vector $\mu=\left(\mu_{1}, \mu_{2}, \cdots, \mu_{K}\right)$, which is divided by the sum of its elements such that we define the organizational appropriation capacity as the K-uple vector $M=\left(M_{1}, M_{2}, \cdots, M_{K}\right)$, where $M_{i}=\frac{\mu_{i}}{\sum_{j=1}^{j=K} \mu_{j}}$. The exogenous appropriation capacity of firm $i$ increases with $\mu_{i}$ and decreases with $\mu_{-i}$. In parallel, the endogenous ability to appropriate is positively affected by the budget that the firm does not dedicate to value creation, that is, $\left(I-\alpha_{i}\right) n_{i}$, and negatively affected by the amount of the partners' budget kept for appropriation, that is, $\left(I-\alpha_{-i}\right) n_{-i}$. We thus define the value appropriation capacity of firm i, $A_{i}$, as a function of the vector $\alpha=\left(\alpha_{1}, \alpha_{2}, \ldots, \alpha_{K}\right) \equiv\left(\alpha_{i}, \alpha_{-i}\right)$ for the focal firm $i$. The set of possible coopetitive agreements is given by $\mathrm{A}=\left\{\alpha, \alpha_{i} \in[0,1]\right.$ for $\left.i=1, \ldots, K\right\}$. Let us note $\alpha^{0}=(0,0, \ldots, 0)$ for the null vector and $\alpha^{\prime}=(||,, \ldots, \mid)$ for the full contribution vector. For our purpose, we rely on contest functions (Buchanan, Tollinson, \& Tullock, 1980) and adopt the following specification:

$$
A_{i}\left(\alpha_{i}, \alpha_{-i}\right)=\left\{\begin{array}{c}
M_{i} \cdot \frac{\left(I-\alpha_{i}\right) n_{i}}{\sum_{j=1}^{j=K}\left(I-\alpha_{j}\right) n_{j}} \text { if } \alpha \neq \alpha^{0} \text { and } \alpha \neq \alpha^{\prime} \\
1 / K \text { if } \alpha=\alpha^{0} \\
0 \text { if } \alpha=\alpha^{\prime} .
\end{array}\right.
$$

The appropriation function $A_{i}\left(\alpha_{i}, \alpha_{-i}\right)$ decreases in $\alpha_{i}$, which indicates the trade-off that firms have to make in terms of budget allocation between value creation and appropriation activities. This appropriation function can be seen as a way to model the competition between the differentiated products. As in any contest game, when the focal firm invests more in its appropriation activities, its likelihood of being chosen by consumers increases such that its 'market share' will be larger in the market generated by the coopetitive project.

The profit of firm i from the coopetitive project depends on the common value created by all partners $(V)$ and its appropriation capacity $\left(A_{i}\right)$ as follows:

$$
\begin{aligned}
\pi_{i}\left(\alpha_{i}, \alpha_{-i}\right) & =V \cdot A_{i} \\
& =\sum_{l=1}^{l=K} \alpha_{l} n_{l} \cdot M_{i} \cdot \frac{\left(I-\alpha_{i}\right) n_{i}}{\sum_{j=1}^{j=k}\left(I-\alpha_{j}\right) n_{j}} \\
& =M_{i} \cdot \sum_{l=1}^{l=K} \alpha_{i} n_{l} \cdot \frac{\left(I-\alpha_{i}\right) n_{i}}{\sum_{j=l}^{j=K}\left(I-\alpha_{j}\right) n_{j}},
\end{aligned}
$$

where $M_{i}$ is a firm-specific parameter that is strictly positive. Note that for $\alpha^{0}$ and $\alpha^{\prime}, V=0$ such that each firm makes zero profit from the coopetitive agreement. If $\alpha_{i}=1, \mathrm{~A}_{i}=0$ and firm i makes zero profit. Therefore, $\alpha_{i}=1$ cannot be a profit-maximizing solution for firm $i$. On the other hand, firm i can eventually choose $\alpha=0$, that is, firm i can be better off by contributing zero to value creation and instead by appropriating maximally. In the next section, we discuss the conditions for which such a solution arises within a coopetitive agreement.

Two comments about our specification of the profit functions are required. First, we assume that firms do not incur specific fixed costs for the coopetitive project. Although fixed costs are relevant, we assume that such costs are associated with the focal firm itself rather than with the coopetitive project (Gnyawali \& Park, 20II). Second, we assume that $\mu=\left(\mu_{1}\right.$, $\left.\mu_{2}, \ldots, \mu_{k}\right)$ is exogenous, that is, these parameters are not affected by the budget allocations of the coopetitive firms. From a dynamic perspective, this implies that the firm-specific organizational capacities to appropriate value do not change over the duration of the coopetitive agreement either during the coopetitive stage or during the competitive stage.

\section{Balancing between value creation and value appropriation activities in innovative coopetition projects}

Building on the game-theoretical approach initiated by Brandenburger and Nalebuff (1996), ${ }^{5}$ we look for the

\footnotetext{
5. See Okura and Carfi (2018) for a recent survey of coopetition and game theory.
} 
equilibrium in terms of value creation and value appropriation that maximizes the profit of each partnering firm. We therefore focus on the profit of the focal firm i. Obviously, because the firms interact with one another, the relevant equilibrium concept is the Nash equilibrium, where the assumption is that each firm chooses a strategy that is a best response to its expectations about its partners' strategies. The Nash equilibrium of the model solves the following system of first-order conditions (FOC) where $K \geq 2$ :

$$
\begin{aligned}
& \forall K \geq 2, \forall n_{i}>I \\
& \frac{\partial \pi_{i}}{\partial \alpha_{i}}=\frac{\partial A_{i}}{\partial \alpha_{i}} V+A_{i} \frac{\partial V}{\partial \alpha_{i}}=0, \forall i=1, \ldots, K .
\end{aligned}
$$

The first term is firm i's marginal return of increasing its share devoted to the common value creation, and the second term is its marginal return of increasing its endogenous appropriation capacity. As discussed above, the first term is positive, and the second term is negative. Therefore, at equilibrium, firm $i$ equalizes the marginal return of the value creation activity to the marginal return of the appropriation activity.

Once detailed, we have the following FOC:

$$
\begin{aligned}
\frac{\partial \pi i}{\partial \alpha i}=M_{i}\left[\frac{\left(I-\alpha_{i}\right) n_{i}^{2} N-n_{i}\left[\sum_{j=1}^{j=k}\left(I-\alpha_{j}\right) n_{j}\right]\left(\sum_{j=1}^{j=k} \alpha_{j} n_{j}\right)}{\left[\sum_{j=1}^{j=k}\left(I-\alpha_{j}\right) n_{j}\right]^{2}}\right] \\
=0, \forall i=1, \ldots, K .
\end{aligned}
$$

Solving this system provides the firms' best reply functions that define the optimal share of the budget to invest in value creation (the proof is given in Appendix 2):

$$
\begin{aligned}
& \alpha_{i}^{*}= \\
& \left\{\begin{array}{cc}
\frac{K^{2}-(K-1)}{K^{2}}-\frac{K-1}{K^{2}} \cdot \frac{N_{-i}}{n_{i}} \quad \text { if } n_{i}>\sum_{j \neq i} n_{j} \cdot \frac{K-1}{K^{2}-(K-1)}, \\
0 & \text { otherwise }
\end{array}\right.
\end{aligned}
$$

At the Nash equilibrium, we can identify the amount of the dedicated budget $\left(\alpha_{i}^{*} n_{i}\right)$ that is allocated to value creation by each firm and the amount that is retained for appropriating the common value created by the project, that is, $\left(I-\alpha_{i}^{*}\right) n_{i}$. It is interesting to observe that at equilibrium, the fraction allocated by firm $i$ to common value creation is decreasing in other firms' total budgets $\left(N_{-i}\right)$ and increasing in firm i's total budget for the coopetitive project $\left(n_{i}\right)$. This fact has implications on firm i's reaction to a change in the distribution of budgets across partners. Expression (6) shows that if $n_{i}$ is sufficiently small, $\alpha_{i}^{*}$ could eventually become negative. By assumption, however, $\alpha_{i}^{*}$ is constrained to be non-negative. The corner solution $\alpha_{i}^{*}=0$ is chosen by firm $i$ if its budget allocated for the coopetitive project is small relative to the aggregate budget of the other members. For instance, in the case of a dyad, from a mathematical standpoint, firm $i$ should free-ride on firm $j$ if $n_{i} \leq \frac{1}{3} n_{j}$. Note that firm $j$ has nevertheless an incentive to invest in the coopetitive project as long $\alpha_{j} M_{j}>$ I. More generally, any firm $i$ for which $n_{i}<\frac{K-1}{K^{2}-(K-l)} \cdot \sum_{j \neq i} n_{j}$
chooses $\alpha_{i}^{*}=0$.

Given the equilibrium values of investment shares $\alpha_{i}^{*}$ for each firm $i$, one can also easily compute the equilibrium profit $\left(\pi_{i}^{*}\right)$ of each firm:

$$
\pi_{i}^{*}=M_{i} \cdot \frac{\sum_{j=1}^{j=k} \alpha_{j}^{*} n_{j}}{K} .
$$

Note that the profits reached by the partnering firms differ only because of their different exogenous and specific capacity to appropriate value. Therefore, under such equal capacity, the coopetitive project leads to the remarkable outcome that profits are equalized among all firms. The equilibrium outcome is based on the assumption that the amount of the budget allocated by each firm to the coopetitive project is common knowledge - that is, the information regarding the firms' budget for coopetition is fully transparent.

\section{Comparative statics}

In this section, we investigate the impact of various parameters on the incentives for firm $i$ to cooperate. More precisely, we study how the firms' budget allocated to the coopetitive project and the number of firms involved in the agreement affect the individual decision to cooperate. We consider the variations of the parameter values (firm budget and number of firms in the agreement) as exogenous shocks because our aim is not to analyze the origin of these variations but only their impact on the firms' cooperative choice within the coopetitive agreement. The comparative statics of firm i's equilibrium $\left(\alpha_{i}^{*}, \pi_{i}^{*}\right)$ allow us to answer the following questions. ( 1 ) How is the budget allocation of firm $i$ affected by an increase in its dedicated budget $\left(n_{i}\right)$ ? That is, does a firm's cooperativeness increase if its budget 
dedicated to the coopetitive project increases? How does this affect its profit? (2) To what extent is it profitable to involve (eliminate) an additional (standing) partner in the coopetitive agreement? What is the corresponding impact on the cooperation level?

\section{Focal firm's budget and cooperativeness}

In most alliances and coopetition agreements, partners tend to have different budget sizes that can be allocated to the alliance or coopetition projects. A very rich literature has studied the implications of asymmetric alliances for the degree of cooperation among partners and the stability of the agreement (Vandaie \& Zaheer, 20l4; Yang, Zheng, \& Zhao, 20l4). However, most studies in the coopetition literature consider partners of equal sizes and therefore do not address the effect of the heterogeneity of partners' size on their cooperativeness (see Hora et al. [2018] or Chiambaretto et al. (2020) for recent exceptions). Our framework allows us to address this issue at equilibrium: does a larger coopetitive budget of the focal firm increase its propensity to cooperate in the coopetitive project?

Recall that a larger budget represents an increase in $n_{i}$ To assess the impact of an increase in $n_{j}$ on the cooperativeness of firm $i$, we examine the sign of $\frac{\partial \alpha_{i}^{*}}{\partial n_{i}}$. We find that

$$
\frac{\partial \alpha_{i}^{*}}{\partial n_{i}}=\frac{(K-l) \cdot \sum_{\forall j \neq i} n_{j}}{\left(K n_{i}\right)^{2}}>0 .
$$

A possible interpretation for the positive sign of the derivative relies on the fact that when the focal firm's budget increases, it can create more value and enlarge the size of the market for the coopetitive project by investing more in cooperation while keeping the same share of its coopetitive budget to appropriate the jointly created value. Firms with larger budgets are thus more willing to create value in coopetition than firms with more modest budgets since they know that they can appropriate this value because of their larger budget to differentiate and distribute the final product.

This leads us to the following proposition:

Proposition Ia. An increase in the coopetitive budget of the focal firm leads to an increase in the fraction of the focal firm's budget invested in value creation.

\section{Focal firm's budget and profit level}

Regarding profit, the comparative statics allow us to establish that a larger coopetitive budget of the focal firm increases the focal firm's profit. Accordingly, we have

$$
\begin{gathered}
\frac{\partial \pi_{i}^{*}}{\partial n_{i}}=\frac{M_{i}}{K} \cdot\left(\sum_{j=1}^{j=K} \frac{\partial \alpha_{j}^{*}}{\partial n_{i}} n_{j}+\alpha_{i}^{*}\right) \\
\frac{\partial \pi_{i}^{*}}{\partial n_{i}}=\frac{M_{i}}{K} \cdot\left(-\frac{(K-l)^{2}}{K^{2}}+\frac{(K-l) \cdot \sum_{\forall j \neq i} n_{j}}{K^{2} n_{i}}+\frac{K^{2}-(K-l)}{K^{2}}\right. \\
\left.-\frac{K-1}{K^{2}} \cdot \frac{\sum_{\forall j \neq i} n_{j}}{n_{i}}\right) \\
\frac{\partial \pi_{i}^{*}}{\partial n_{i}}=\frac{M_{i}}{K^{2}}>0 .
\end{gathered}
$$

When the focal firm's coopetitive budget becomes larger, it increases the percentage of this budget allocated to the value creation activity. Even if the level of cooperation of the partners decreases in the focal firm's budget $\left(\frac{\partial \alpha_{j}^{*}}{\partial n_{i}}<0\right.$, see below), this effect is compensated by the joint increase in $\alpha_{i}^{*}$ and $n_{i}$ This trade-off between investing more budget in cooperation to create more joint value (which consequently also benefits the other firms) and saving the budget for appropriation ends in favor of investing most of the additional budget in cooperation instead of competition. This leads to Proposition Ib.

Proposition Ib. An increase in the coopetitive budget of the focal firm increases its profit in the coopetitive agreement.

\section{Partner firm's budget and focal firm's cooperativeness}

We now adopt the opposite perspective and consider instead an increase in a partner's coopetitive budget on the level of cooperation of the focal firm. When cooperating with firms that allocate larger budgets to the coopetition project, the focal firm may face different issues, especially with respect to appropriating the value created in the coopetitive agreement (Bae \& Gargiulo, 2004; Yang et al., 20 I4). To assess the impact on cooperativeness of the focal firm when a partner's coopetitive budget increases, we determine the sign of $\frac{\partial \alpha_{i}^{*}}{\partial n_{j}}$.
We find that

$$
\frac{\partial \alpha_{i}^{*}}{\partial n_{j}}=-\frac{K-1}{K^{2} n_{i}}<0
$$

The negative sign means that an increase in the budget of a firm i's partner reduces the focal firm's proportion of the budget dedicated to value creation. Consequently, the focal firm keeps more budget to appropriate to the jointly created value. 
Firms with smaller coopetitive budgets thus face greater challenges related to value appropriation in alliances with partners that have larger budgets. Keeping more budget to appropriate value allows firms with a lower dedicated budget to maintain their profitability in the coopetitive project. A firm that has less budget vis-à-vis other firms must save it in the cooperative game (value creation) to increase its market share for value appropriation while benefiting from the greater cooperative investments of the other firms (whose budgets are comparatively larger). We thus state the following proposition.

Proposition 2a. A uniform increase in a partner's coopetitive budget reduces the focal firm's cooperativeness.

\section{Partner firm's budget and focal firm's profit level}

Although an increase in the partner firm's coopetitive budget reduces the focal firm's cooperativeness, we suspect that such adjustment is profitable. We can show that the increase of a partner's dedicated budget positively affects the focal firm's profit. Let us compute the sign of $\frac{\partial \pi_{i}^{*}}{\partial n_{j}}$ :

$$
\begin{aligned}
& \frac{\partial \pi_{i}^{*}}{\partial n_{j}}=\frac{M_{i}}{K} \cdot\left(\sum_{k=1}^{k=k} \frac{\partial \alpha_{k}^{*}}{\partial n_{j}} n_{k}+\alpha_{j}^{*}\right) \\
& \frac{\partial \pi_{i}^{*}}{\partial n_{j}}=\frac{M_{i}}{K} \cdot\left(\sum_{k \neq j} \frac{\partial \alpha_{k}^{*}}{\partial n_{j}} n_{k}+\frac{\partial \alpha_{j}^{*}}{\partial n_{j}} n_{j}+\alpha_{j}^{*}\right) \\
& \frac{\partial \pi_{i}^{*}}{\partial n_{j}}=\frac{M_{i}}{K} \cdot\left(-\frac{(K-I)^{2}}{K^{2}}+\frac{(K-I) \cdot \sum_{\forall k \neq j} n_{k}}{K^{2} n_{j}}+\frac{K^{2}-(K-l)}{K^{2}}(I \mid)\right. \\
& \left.-\frac{K-1}{K^{2}} \cdot \frac{\sum_{\forall k \neq j} n_{k}}{n_{j}}\right) \\
& \frac{\partial \pi_{i}^{*}}{\partial n_{j}}=\frac{M_{i}}{K^{2}}>0
\end{aligned}
$$

This leads to the following proposition.

Proposition 2b. An increase in the coopetitive budget of one of the focal firm's partners increases the focal firm's profit in the coopetitive agreement.

In the case of the partners' budget (at least one) becoming larger, the focal firm invests less in cooperation to preserve its monetary resources to face stronger competitors, whereas the partners whose budgets have increased invest more in value creation. The end of the adjustment process leads to an increase not only in the partner firm's profit (Prop Ib) but also in the focal firm's profit. From a global standpoint, a more (less) important coopetitive budget given to the firms if they are considered together, regardless of their distribution among the partners, increases (decreases) the profit of all participating firms.

\section{Number of partners and focal firm's cooperativeness}

Although most coopetitive agreements involve only two actors, one can observe an increasing number of coopetitive agreements that involve more than two competing firms. Different contributions have emphasized the existence of "network coopetition" (Padula \& Dagnino, 2007) or coopetition in ecosystems (Gueguen, 2009). When more than two firms are involved in the coopetitive project, that is, in the presence of multipartner coopetition, the question of the optimum set of partners arises. If more firms are involved, it simultaneously increases the budget for the joint project and the strength of competition among the partners (Chiambaretto \& Dumez, 2016; Das \& Teng, 2002; Heidl, Steensma, \& Phelps, 2014; Lazzarini, 2007). The question of the optimum set of partners is therefore a complex issue. Here, we address a somewhat simpler issue about whether adding (removing) an outside (a current) partner to (from) an already existing agreement positively or negatively influences the profit and cooperativeness of its members. We first assess the impact on cooperativeness, that is, the fraction of the budget allocated to value creation, from a change in the set of partners. We first consider the addition of a new partner before considering the removal of an existing partner.

The marginal impact of an additional member (the $K+I$ th firm) on the level of cooperation of partner $i$ of the standing coopetitive agreement crucially depends on the newcomer's level of dedicated budget. Let us compute the sign of the difference: $\alpha_{i}^{*(K+1)}-\alpha_{i}^{*(K)}$. We obtain

$$
\begin{aligned}
& \alpha_{i}^{*(K+I)}-\alpha_{i}^{*(K)} \\
& =\frac{(K+I)^{2}-K}{(K+I)^{2}}-\frac{K}{(K+I)^{2}} \cdot \frac{N+n_{K+1}-n_{i}}{n_{i}}-\frac{K^{2}-(K-I)}{K^{2}}+\frac{K-I}{K^{2}}
\end{aligned}
$$$$
\frac{N-n_{i}}{n_{i}}
$$$$
=\frac{N\left(K^{2}-(K+I)\right)-K^{3} n_{K+1}}{(K+I)^{2} n_{i} K^{2}} \text {. }
$$

We obtain

$$
\left\{\begin{array}{l}
\alpha_{i}^{*(K+1)}-\alpha_{i}^{*(K)}>0, \text { if } n_{K+1}<N \frac{K^{2}-(K+I)}{K^{3}}, \\
\alpha_{i}^{*(K+1)}-\alpha_{i}^{*(K)} \leq 0, \text { if } n_{K+1} \geq N \frac{K^{2}-(K+1)}{K^{3}} .
\end{array}\right.
$$


According to condition (13), the sign of the difference depends on the coopetitive budget of the new partner. If the new partner's budget is smaller (respectively larger) than some threshold value that depends on the overall budget of the members of the existing agreement $(N)$, the focal firm increases (respectively decreases) its level of cooperation. Thus, by creating more (respectively less) value, the standing members of the agreement compensate for the potential loss (respectively gain) incurred by a larger number of partners involved in the sharing. If the new partner's coopetitive budget is relatively small, the historical members are not threatened by its entrance in the agreement. Therefore, the focal firm can increase its cooperative investment in common value creation. However, if the new partner's coopetitive budget is relatively large, its competitive power threatens the value appropriation capacity of the standing partners. They react by lowering their cooperative investment to secure sufficient appropriation capacity while counting on the new partner to create more value. Figure I represents the boundary percentage of $N$ for $n_{K+1}$ that makes the other $K$ firms increase or decrease their $\alpha^{*}$ by standardizing $N$ to 1.6

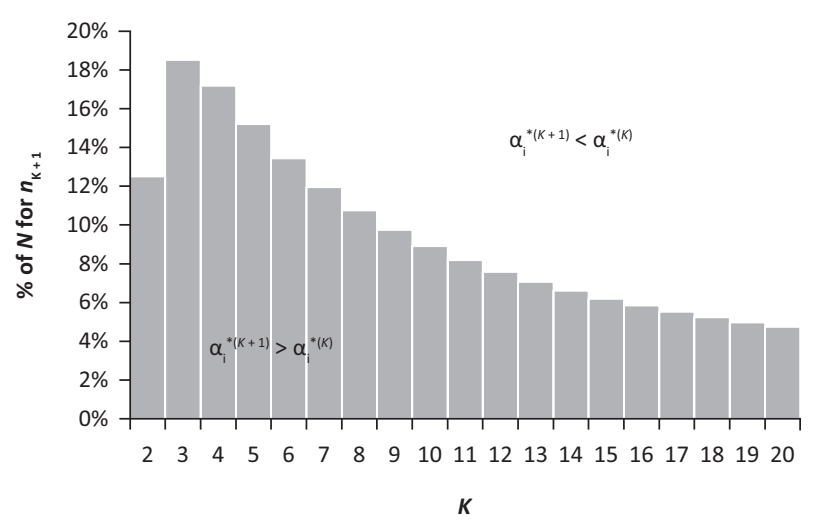

Figure I. Budget of the new partner in the percentage of $N$ that determines the increase or decrease of $\alpha_{i}^{*}$ for the other firms

Note: $\frac{K^{2}-(K+1)}{K^{3}}$ represents the boundary percentage of $N=\sum_{i=1}^{i=k} n_{i}$ for the budget of the new partner $\left(n_{K+1}\right)$, which determines the increase or decrease of the other firms' Nash cooperative investments $\left(\alpha_{i}^{*}\right)$. K is the number of cooperative firms before the cooperation of a new partner.

Two opposite effects drive the evolution of the boundary, namely, a budget effect (i) and a size effect (ii). Adding a new partner to the agreement (i) increases the potential budget to create

\footnotetext{
6. These results are satisfied for all $K>$ I since $\lim _{K \rightarrow+\infty} \frac{K^{2}-(K+I)}{K^{3}}=0$. Even if $K$ is very large, the boundary remains above $0\left(K^{2}-(K+1)>0\right.$ for all $K>1$ ), which means that there is always at least one case where cooperation can increase with the number of players (as long as the $K+I$ th firm has a coopetitive budget very close to 0 ).
}

common value, which allows firms to be less cooperative ( $\alpha$ decreasing) and still create more value overall, but the size effect (ii) also increases the number of partners that appropriate this value, which pushes firms to be more cooperative (increasing $\alpha$ ) to create more value and maintain at least the same level of profit. In our case, moving from a two-firm agreement to a three-firm agreement makes the size effect (ii) greater than the budget effect (i), which is reversed when moving from a three-firm agreement to a four-(or more)-firm agreement. Roughly, moving from two to three firms represents an increase of 50\% (which is relatively huge), while moving from three to four firms represents an increase of 25\%. This explains why the boundary increases between $K=2$ and $K=3$ while decreasing otherwise.

Based on these results, we state Proposition 3a.

Proposition 3a. Adding a new partner to an existing coopetitive agreement increases the focal firm's cooperativeness if and only if the new partner's budget is sufficiently small (i.e., below the boundary percentage of $\mathrm{N}$ displayed in Figure 1).

We can also interpret this result from the reverse perspective. What occurs if a firm exits the agreement? The corollary of Proposition 3a suggests that the remaining firms increase (resp. decrease) their cooperation levels if the exiting firm's budget is larger (respectively lower) and decrease their cooperation levels if they lose a partner with a small coopetitive budget.

Corollary of Proposition 3a. Removing a partner from an existing coopetitive agreement increases the focal firm's cooperativeness if and only if the exiting partner's budget is sufficiently large (i.e., above the boundary percentage of $\mathrm{N}$ displayed in Figure I).

\section{Number of partners and the focal firm's profit level}

Regarding profit, it is crucial to understand the impact of adding a new partner to the standing coopetitive agreement on the profit of the focal firm. The Nash profit is determined by budget $\alpha_{i}^{*} n_{i}$ invested in cooperation for value creation:

$\alpha_{i}^{*} n_{i}=\frac{n_{i}\left(K^{2}-(K-I)\right)}{K^{2}}-\frac{K-1}{K^{2}} \cdot\left(N-n_{i}\right)=n_{i}-N \frac{K-1}{K^{2}}$.

Firm i's profit, as a function of $K$, is given by

$$
\begin{aligned}
\pi_{i}^{*}(K) & =M_{i} \cdot \frac{\sum_{j=1}^{j=K} \alpha_{j}^{*} n_{j}}{K}=M_{i} \cdot \frac{\sum_{j=1}^{j=K}\left(n_{j}-N \frac{K-1}{K^{2}}\right)}{K} \\
& =M_{i} \cdot \frac{N}{K}\left(1-\frac{K-1}{K}\right) .
\end{aligned}
$$

After adding a new partner to the agreement, the profit of the focal firm $i$ becomes 


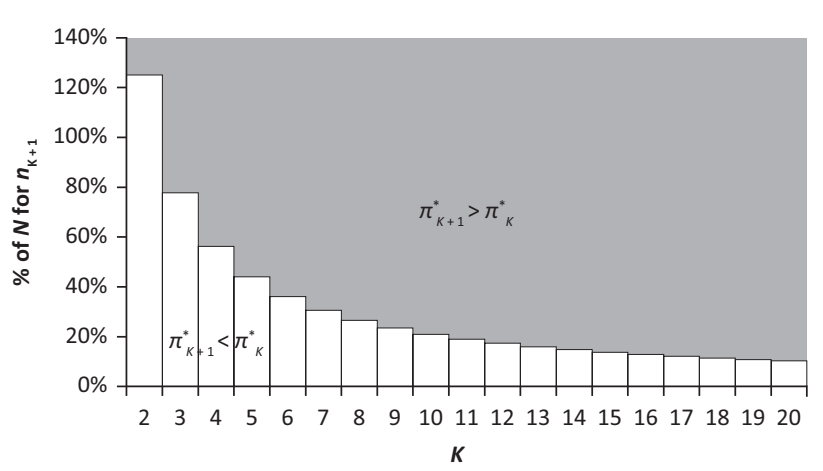

Figure 2. Budget of the new partner in the percentage of $N$ that determines the increase or decrease of $\pi^{*}$ for the other firms Notes: $\frac{2 K+1}{K^{2}}$ represents the boundary percentage of $N=\sum_{i=1}^{i=K} n_{i}$ for the budget of the new partner $\left(n_{K+1}\right)$, which determines the increase or decrease of the other firms' Nash profit $\left(\pi^{*}\right) . K$ is the number of cooperative firms before the cooperation of a new partner.

$$
\pi_{i}^{*}(K+I)=M_{i} \cdot \frac{N+n_{k+1}}{K+1}\left(1-\frac{K}{K+1}\right) .
$$

To assess the impact of the addition of a partner on the Nash profit of the focal firm, let us determine the sign of $\pi_{i}^{*}(K+I)-\pi_{i}^{*}(K)$. Observe that

$$
\begin{aligned}
\pi_{i}^{*}(K+1)-\pi_{i}^{*}(K) & =M \cdot\left(\frac{N+n_{k+1}}{K+1}\left(1-\frac{K}{K+1}\right)-\frac{N}{K}\left(1-\frac{K-1}{K}\right)\right) \\
& =M_{i} \cdot \frac{K\left(N+n_{k+1}\right) \frac{1}{K+1}-N(K+1) \frac{1}{K}}{K(K+1)} .
\end{aligned}
$$

We obtain

$$
\left\{\begin{array}{l}
\pi_{i}^{*}(K+1)-\pi_{i}^{*}(K)>0 \text {, if } n_{K+1}>N \frac{2 K+1}{K^{2}}, \\
\pi_{i}^{*}(K+1)-\pi_{i}^{*}(K) \leq 0, \text { if } n_{K+1} \leq N \frac{2 K+1}{K^{2}} .
\end{array}\right.
$$

For instance, if $K=2$, then the two standing firms benefit from cooperating with a third partner only if the new partner has a very large coopetitive budget $\left(n_{K+1}>\frac{5}{4} N\right)$. Figure 2 shows the evolution of this threshold as $K$ increases. When the number of initial partners is small, the additional partner's budget must be very large to increase the Nash profit of the focal firm. The threshold appears to decrease at approximately 10\% of $N$ when $K$ is approximately equal to 20 firms in the coopetitive game. The threshold is always positive but approaches 0 when $K$ reaches infinity. Thus, when a small number of firms sign the coopetitive agreement, the initial partners usually do not have sufficient incentives to accept an additional partner, unless it provides a very large coopetitive budget. Conversely, losing a partner with a large budget decreases the profit of the remaining firms; however, losing a partner with a relatively small budget is always profitable for them.

These results allow us to formulate the following propositions.

Proposition 3b. Adding a new partner to a standing coopetitive agreement increases the Nash profit of the focal firm if and only if the new partner's dedicated budget is sufficiently large (i.e., above the boundary percentage of $\mathrm{N}$ displayed in Figure 2).

Corollary of Proposition 3b. Removing a partner from an existing coopetitive agreement increases the focal firm's profit if and only if the exiting partner's budget is sufficiently small (i.e., below the boundary percentage of $\mathrm{N}$ displayed in Figure 2).

Before discussing the implications of these results in the following section, Table I provides a summary of the results of the comparative statics of the model showing whether there is a positive or negative relationship among the budget size of the focal firm, the budget size of the other partners, the entry or exit of a partner with a small or a large coopetitive budget in the agreement, and the cooperation level and profit of the focal firm.

\section{Discussion}

\section{Finding the right balance between value creation and value appropriation in the coopetition for innovation}

The existing literature on coopetition has emphasized the necessity to find the right balance between value creation and value appropriation activities to maximize the focal firm's innovation performance (Park et al., 20l4; Ritala \& HurmelinnaLaukkanen, 20l8; Ritala \& Tidström, 20l4). However, these contributions remained mainly qualitative (Gnyawali \& Park, 201 I; Ritala \& Tidström, 20l4) or when quantitative assessments were made, the level of analysis was not at the agreement level (Park et al., 20 I4). Despite several calls to investigate this issue more deeply, there has been a lack of research on how firms can find this optimal balance. Our research answers this call by investigating the value creation/appropriation dilemma in coopetition and provides several key differentiating contributions. First, our game-theoretical approach allows us to identify the equilibrium allocation of the budget for each

\footnotetext{
7. This means that when $K$ is very large, there is always at least one case where profits can increase with the number of partners if the $K+I$ th firm has a coopetitive budget very close to 0 .
} 
Table I. Summary of the comparative statics: changes in the cooperation level and profit according to the focal firm's budget size, partner firms' budget size, and number of partners

\begin{tabular}{lc}
\hline & Cooperation \\
Increase in focal firm's budget size & + \\
Increase in a partner firm's budget size & - \\
A firm with a large budget joins (exits) the agreement & $-(+)$ \\
A firm with a small budget joins (exits) the agreement & $+(-)$ \\
\hline
\end{tabular}

Notes:The positive and negative signs indicate, at the equilibrium, a positive or negative change in the cooperation level and profit of the focal firm or its partners in response to a change in the focal firm's budget size and in its partner firms' budget size and the entry (or exit) of a firm with a large or small budget in the coopetitive agreement.

participant involved in the agreement between value creation activities and value appropriation activities. Second, in opposition with previous contributions using a two-stage game, we adopt a single-stage approach to take into account the specificities stemming from the simultaneity of competition and cooperation in coopetition. Third, we adopt a perspective in which the partnering firms have a limited budget such that allocation decision made for value creation are made at the expense of value appropriation. Fourth, our modeling allows us to analyze the value creation/appropriation dilemma in settings involving more than two partners with different budgets. Finally, our approach allows us to realize some comparative statics and observe how the equilibrium evolves when the characteristics of the agreement change.

Our research yields several key results. First, we have shown the existence of a unique Nash equilibrium of a coopetitive agreement that determines the amount of budget invested by each member firm in value creation activities and the budget kept by each firm for value appropriation activities. We show that the level of cooperation, that is, the total amount of budget invested cooperatively, depends on the focal firm's coopetitive budget, the partner firms' coopetitive budget and the number of partnering firms. These findings confirm the importance of the variables identified in Ritala and HurmelinnaLaukkanen (2018) and Ritala and Tidström (2014), even if we go beyond these studies in clarifying their respective roles.

Second, our approach emphasizes a key outcome regarding the distribution of the value created by the coopetitive agreement among partnering firms. At the Nash equilibrium, the profits of the partnering firms tend to become equalized. Specifically, the profits reached by the partnering firms differ only based on exogenous organizational appropriation factors. Therefore, by neglecting such exogenous differences, we obtain the remarkable outcome that profits are equalized among all firms despite their heterogeneity in the dedicated budgets to the coopetitive project. The appropriation capacity measured by firms' relative budgets explains why their opposite incentives (to cooperate or compete more) do not have the same effect on their profit. The incentive to allocate a larger proportion of a firm's budget to cooperation (which increases value creation) is stronger for firms with large budgets than for firms with more modest budgets. This result is noteworthy because it shows how the very nature of coopetition contributes not only to generating tensions but also to regulating them by avoiding unequal sharing schemes (Ritala \& HurmelinnaLaukkanen, 20 I 8). This situation holds if every partner can observe or anticipate the total budget of the other partners (without having access to each individual budget). We further discuss this assumption in the following sections.

\section{Understanding the impacts of the firms' budgets and the number of coopeting firms on the focal firm's cooperativeness and profit}

Finding the optimal level of cooperation and the resulting profit in a coopetitive setting also requires an understanding of how firms' strategic reactions evolve according to various parameters. Three variables have been investigated: the focal firm's budget dedicated to the coopetitive project, the partner firm's increase in its budget, and the total number of partnering firms.

First, we show that when the budget of the focal firm increases, the amount of the budget invested cooperatively to create value also increases. A richer focal firm has incentives to foster value creation in the coopetitive project by investing a larger amount of its budget in cooperation while keeping the same amount of budget to appropriate the jointly created value. Richer firms are thus more willing to create value in coopetition than firms with lower budgets. Additionally, we show that when the coopetitive budget of the focal firm increases, the additional value created by the focal firm increases its profit. In this case, more cooperation from the focal firm with the larger budget overcompensates for the decrease in the cooperation of the other partners.

Second, by adopting a symmetrical approach, we have investigated the impact of increasing the budget of a partnering firm 
on the focal firm's strategic reaction. Our model allows us to conclude that when the budget of a partner firm increases, the focal firm reduces its share of budget invested cooperatively while keeping more budget to appropriate the joint value. Indeed, partners with relatively smaller budgets face greater challenges regarding value appropriation in alliances with partners that invest a lot in coopetition activities (Yang et al., 20 I4). Consequently, keeping a larger amount of the budget to appropriate value is the only way for smaller partners to remain profitable in a coopetitive project. Regarding profits, we show that even if a partner firm increases its budget dedicated to the coopetitive project, the focal firm will also see its profit increase. This result contradicts several contributions on asymmetric alliances that state that partnering with a large firm usually reduces the profit of a smaller partner (Bae \& Gargiulo, 2004; Vandaie \& Zaheer, 2014). We explain this contradiction by noting that most of these previous contributions have focused on value appropriation mechanisms without accounting for the added value of cooperating with a partner that has a larger coopetitive budget. Even if a smaller firm has a lower market share (compared to the initial situation), it also benefits from the increased market size and consequently realizes more profit.

Finally, this research has shown that the impact of adding new members on coopetitive agreements has contrasting outcomes for the initial partners. First, when a new member joins a coopetitive agreement, the focal firm invests a larger share of its budget cooperatively to create value only if the new partner is relatively small (from a budgetary standpoint). In the presence of a small new partner, the focal firm invests a larger share of its budget to create more value and to compensate for the loss of total value that can be appropriated because it is now shared with one more firm. However, if the new partner has a large budget dedicated to the coopetitive project, then this budget represents a threat to the focal firm regarding value appropriation, which leads to a downward adjustment of the focal firm's investment in cooperation to keep a sufficient budget to maintain its market share while expecting the new partner to create more value, which occurs at equilibrium. Regarding profit, the situation is even more complicated. The model allows us to conclude that the focal firm's profit increases only if the new partner is sufficiently large (from a budgetary standpoint). The addition of a new partner makes sense only if it creates more value (by adding enough monetary resources to the common pool) than it appropriates (by dividing the value with an additional partner). Thus, only a large partner appears to allow firms to create more value rather than appropriating it. Consequently, if the partnering firms decide to accept a new member in the coopetitive agreement, then this new partner must bring a sufficiently large coopetitive budget, and such a situation leads to a reduction of the budget cooperatively invested by the partnering firms in value creation.

\section{Conclusion}

Our research aimed at understanding how firms balance value creation and value appropriation behaviors in innovative coopetition projects. More precisely, based on a formal framework dedicated to coopetition agreements, we investigated the impacts of firms' budget and the number of partners in the coopetitive agreement on the balance between value creation and value appropriation strategies. In this sense, our article contributes to the coopetition literature by offering new insights into the debate concerning the value creation and value appropriation strategies adopted by coopeting firms (Ritala \& Hurmelinna-Laukkanen, 2009, 2018; Ritala \& Tidström, 2014) and the tensions that they generate (Fernandez et al., 20l4; Fernandez \& Chiambaretto, 2016; Tidström, 20।4). This vast literature has identified the key determinants of these strategies but has not provided an integrative framework to study their respective impacts on firms' value creation and appropriation strategies. Furthermore, our contribution is one of the first studies that investigates situations of "asymmetric coopetition" in which partners have different sizes and "multipartner coopetition" in which there are three or more partners. Therefore, we emphasize the importance of the relative sizes (from a budgetary standpoint) of the partners in explaining value creation and value appropriation strategies.

Inevitably, our study has a number of limitations. As with any theoretical model, our model is based on a series of assumptions that must be discussed. First, our model allows firms to use and allocate their budget for value creation or value appropriation interchangeably. Most of our results depend on this key assumption of investment substitutability across partners. However, resources dedicated by different firms to a coopetitive project are rarely perfect substitutes and frequently involve complementarities (or synergies) between resources. It would therefore be of interest to extend our model to other settings that allow for complementarities (e.g., with a multiplicative value creation function). Second, our results hold only if the coopetitive budgets of partnering firms are observable and common knowledge. Future research could consider asymmetric information among the partnering firms or develop a model in which the appropriation efforts are more difficult to observe than the value creation efforts. Finally, as with any theoretical paper, further research is needed to empirically assess the validity of our conclusions. This empirical test could be conducted either by relying on existing databases or by running controlled laboratory experiments.

Nevertheless, this research provides new insights regarding the value creation/value appropriation dilemma in coopetition strategies for innovation while identifying promising research avenues for future contributions. 


\section{Acknowledgments}

The authors would like to thank the Associate Editor Simon Porcher and the anonymous reviewers for their insightful suggestions and comments, which greatly contributed to improve this manuscript. The authors also thank the following researchers for their helpful insights and observations: Jamal Azzam, Héloïse Berkowitz, Anne-Sophie Fernandez, Frédéric Le Roy, Nicola Mirc, and Petros Sekeris.

\section{Conflict of interest and funding}

The authors report no conflicts of interest. This research benefitted from the financial support of the Labex Entreprendre.

\section{References}

Adegbesan, J. A. \& Higgins, M. J. (20 I I). The intra-alliance division of value created through collaboration. Strategic Management Journal, 32(2), |87-2 | I. doi: |0. 1002/smj.872

Ansari, S. (Shaz), Garud, R. \& Kumaraswamy, A. (20I6). The disruptor's dilemma: TiVo and the U.S. television ecosystem. Strategic Management Journal, 37(9), I 829-1853. doi: 10. I 002/smj.2442

Bae, J. \& Gargiulo, M. (2004). Partner substitutability, alliance network structure and firm profitability in the telecommunications industry. Academy of Management Journal, 47(6), 843-859. doi: urn:nbn:nl:ui: I 2-I 48536

Bengtsson, M. \& Kock, S. (2000). "Coopetition" in business networks - To cooperate and compete simultaneously. Industrial Marketing Management, 29(5), 4 I I-426. doi: I 0. I 1 I 6/S00 I 9-850 I (99)00067-X

Bengtsson, M. \& Kock, S. (20I4). Coopetition - Quo vadis? Past accomplishments and future challenges. Industrial Marketing Management, 43(2), I80-188. doi: I0.1016/j.indmarman.2014.02.015

Bengtsson, M., Raza-Ullah, T. \& Vanyushyn, V. (2016). The coopetition paradox and tension: The moderating role of coopetition capability. Industrial Marketing Management, 53, 19-30. do: I 0. I 0 | 6/j.indmarman.20 I 5. I l.008

Bouncken, R. B. \& Kraus, S. (20।3). Innovation in knowledge-intensive industries: The double-edged sword of coopetition. Journal of Business Research, 66(10), 2060-2070. doi: I0.10 I6/j.jbusres.20I3.02.032

Brandenburger, A. M. \& Nalebuff, B. J. (1996). Co-opetition: A revolutionary mindset that redefines competition and cooperation (Vol. I21). New York, NY: Doubleday.

Brandenburger, A. \& Stuart, H. (2007). Biform games. Management Science, 53(4), 537-549. doi: | 0.1287/mnsc. 1060.059|

Buchanan, J., Tollinson, R. \& Tullock, G. (1980). Toward a theory of the rent-seeking society. Texas, US: College Station.

Chiambaretto, P., Bengtsson, M., Fernandez, A.-S. \& Näsholm, M. H. (2020). Small and large firms' trade-off between benefits and risks when choosing a coopetitor for innovation. Long Range Planning, 53(I), I0 I 876. doi: 10.1016/j.Irp.2019.03.002

Chiambaretto, P. \& Dumez, H. (2016). Toward a typology of coopetition: A multilevel approach. International Studies of Management \& Organization, 46(2-3), I I0-129. doi: I 0.1080/00208825.2015.1093797

Chou, H.-H. \& Zolkiewski, J. (20।8). Coopetition and value creation and appropriation: The role of interdependencies, tensions and harmony. Industrial Marketing Management, 70, 25-33. doi: I0. I I I 6/j.indmarman.20 I 7.08.0I 4

Cohen, W. M. \& Levinthal, D. A. (1990). Absorptive capacity: A new perspective on learning and innovation. Administrative Science Quarterly, 35(I), 128. doi: 10.2307/2393553
Das, T. K. \& Teng, B.-S. (2002). Alliance constellations: A social exchange perspective. Academy of Management Review, 27(3), 445-456. doi: | 0.5465/amr.2002.7389937

D'Aspremont, C. \& Jacquemin, A. (1988). Cooperative and non-cooperative R\&D in duopoly with spillovers. American Economic Review, 78, | | 33-| | 37. Retrieved from http://www.jstor.org/stable//807|73

Dorn, S., Schweiger, B. \& Albers, S. (2016). Levels, phases and themes of coopetition: A systematic literature review and research agenda. European Management Journal, 34(5), 484-500. doi: I0. I 0 I6/j.emj.20 I6. 02.009

Fernandez, A., Chiambaretto, P., Le Roy, F. \& Czakon, W. (2018). The Routledge companion to coopetition strategies. Abingdon: Routledge.

Fernandez, A.-S. \& Chiambaretto, P. (2016). Managing tensions related to information in coopetition. Industrial Marketing Management, 53, 66-76. doi: 10.1016/j.indmarman.2015.11.010

Fernandez, A.-S., Le Roy, F. \& Gnyawali, D. R. (2014). Sources and management of tension in co-opetition case evidence from telecommunications satellites manufacturing in Europe. Industrial Marketing Management, 43(2), 222-235. doi: 10.1016/j.indmarman. 2013.11.004

Gans, J. \& Ryall, M. D. (20 I7).Value capture theory:A strategic management review. Strategic Management Journal, 38(I), I7-4I. doi: I 0. I 002/smj.2592

Garfinkel, M. R. \& Skaperdas, S. (2007). Economics of conflict: An overview. In T. Sandler \& K. Hartley (Eds.), Handbook of defense economics (pp. 649-710). Amsterdam: Elsevier.

Gast, J., Hora, W., Bouncken, R. B. \& Kraus, S. (20 I8). Challenges and merits of coopetitive innovation. In A. Fernandez, P. Chiambaretto, F. Le Roy \& W. Czakon (Eds.), The Routledge Companion to Coopetition Strategies (pp. 283-297). Abingdon: Routledge.

Gnyawali, D. R. \& Park, B.-J. (201 I). Co-opetition between giants: Collaboration with competitors for technological innovation. Research Policy, 40(5), 650-663. doi: 10.1 01 6/j.respol.201 I.01.009

Gnyawali, D. R. \& Ryan Charleton, T. (20 I8). Nuances in the interplay of competition and cooperation: Towards a theory of coopetition. Journal of Management, 44(7), 25 I I-2534. doi: I 0. I I77/0 | 492063 | 8788945

Grünfeld, L. A. (2003). Meet me halfway but don't rush: Absorptive capacity and strategic R\&D investment revisited. International Journal of Industrial Organization, 2 I (8), | 091-1 109. doi: 10.1016/50167-7| 87 (03)00076-6

Gueguen, G. (2009). Coopetition and business ecosystems in the information technology sector: The example of Intelligent Mobile Terminals. International Journal of Entrepreneurship and Small Business, 8(I), I 35-153. doi: I0.1504/IJESB.2009.024I 09

Haavelmo, T. (1954). A study in the theory of economic evolution. Amsterdam: North-Holland Publishing Company.

Heidl, R. A., Steensma, H. K. \& Phelps, C. (20I4). Divisive faultlines and the unplanned dissolutions of multipartner alliances. Organization Science, 25(5), | 35 |-137| . doi: | 0. I287/orsc.20|4.0898

Hirshleifer, J. (1989). Conflict and rent-seeking success functions: Ratio vs. difference models of relative success. Public Choice, 63, I01-1 12. doi: 10.1007/BF00I53394

Hirshleifer, J. (1991). The paradox of power. Economics and Politics, 3, |77-200. doi: 10.1 | | |/j. 1468-0343.1991.tb00046.x

Hora, W., Gast, J., Kailer, N., Rey-Marti, A. \& Mas-Tur, A. (2018). David and Goliath: Causes and effects of coopetition between start-ups and corporates. Review of Managerial Science, 12(2), 4I I-439. doi: 10.1007/ sl I 846-0 17-0273-9

Kamien, M. I. \& Zang, I. (2000). Meet me halfway: Research joint ventures and absorptive capacity. International Journal of Industrial Organization, 18(7), 995-1012. doi: 10.1016/50 167-7|87(00)00054-0 
Lado, A. A., Boyd, N. G. \& Hanlon, S. C. (1997). Competition, cooperation, and the search for economic rents: A syncretic model. Academy of Management Review, 22 ( ), I I0-14 I. doi: I0.5465/amr. 1997.9707 | 8026 |

Lavie, D. (2007). Alliance portfolios and firm performance: A study of value creation and appropriation in the U.S. software industry. Strategic Management Journal, 28(12), I 187-12 12. doi: 10.1002/smj.637

Lazzarini, S. G. (2007). The impact of membership in competing alliance constellations: Evidence on the operational performance of global airlines. Strategic Management Journal, 28(4), 345-367. doi: I0. I 002/smj.587

Le Roy, F. \& Czakon, W. (2016). Managing coopetition:The missing link between strategy and performance. Industrial Marketing Management, 53 , 3-6. doi: | 0. I0 |6/j.indmarman.20 15.1 I.005

Le Roy, F. \& Fernandez, A.-S. (20I5). Managing coopetitive tensions at the working-group level: The rise of the Coopetitive Project Team. British Journal of Management, 26(4), 67 |-688. doi: I 1. I | | |/|467-855 I. I 2095

Le Roy, F., Fernandez, A.-S. \& Chiambaretto, P. (20।8). From strategizing coopetition to managing coopetition. In A. Fernandez, P. Chiambaretto, F. Le Roy \& W. Czakon (Eds.), The Routledge companion to coopetition strategies (pp. 36-46). Abingdon: Routledge.

MacDonald, G. \& Ryall, M. D. (2004). How do value creation and competition determine whether a firm appropriates value? Management Science, 50(I0), I319-1333. doi: I0.1287/mnsc. I030.0152

Okura, M. \& Carfi, D. (20।8). Coopetition and game theory. In A. Fernandez, P. Chiambaretto, F. Le Roy \& W. Czakon (Eds.), The Routledge companion to coopetition strategies (pp. 139-146). Abingdon: Routledge.

Padula, G. \& Dagnino, G. (2007). Untangling the rise of coopetition: The intrusion of competition in a cooperative game structure. International Studies of Management and Organization, 37(2), 32-52. doi: 10.2753/ IMO0020-8825370202

Panico, C. (2017). Strategic interaction in alliances. Strategic Management Journal, 38(8), 1646-1667. doi: 10.1002/smj.2610

Park, B.-J. (Robert), Srivastava, M. K. \& Gnyawali, D. R. (20I4). Walking the tight rope of coopetition: Impact of competition and cooperation intensities and balance on firm innovation performance. Industrial Marketing Management, 43(2), 210-221. doi: 10.1016/j.indmarman.2013.1 I.003

Ritala, P. (2012). Coopetition strategy - When is it successful? Empirical evidence on innovation and market performance. British Journal of Management, 23(3), 307-324. doi: I 0.1 | | |/j. I 467-855 I.201 I.00741.x

Ritala, P. (20।8). Coopetition and market performance. In A. Fernandez, P. Chiambaretto, F. Le Roy \& W. Czakon (Eds.), The Routledge companion to coopetition strategies (pp. 317-325). Abingdon: Routledge.
Ritala, P. \& Hurmelinna-Laukkanen, P. (2009). What's in it for me? Creating and appropriating value in innovation-related coopetition. Technovation, 29(12), 819-828. doi: 10.1016/j.technovation.2009. 07.002

Ritala, P. \& Hurmelinna-Laukkanen, P. (20 I 3). Incremental and radical innovation in coopetition - The role of absorptive capacity and appropriability. Journal of Product Innovation Management, 30(1), 154-169. doi: I 0. 1 | | | |/j. I540-5885.20 I2.00956.x

Ritala, P. \& Hurmelinna-Laukkanen, P. (20 I 8). Dynamics of coopetitive value creation and appropriation. In A.-S. Fernandez, P. Chiambaretto, F. Le Roy \& W. Czakon (Eds.), The Routledge companion to coopetition strategies (pp. 58-67). Abingdon: Routledge.

Ritala, P. \& Tidström, A. (20|4). Untangling the value-creation and valueappropriation elements of coopetition strategy: A longitudinal analysis on the firm and relational levels. Scandinavian Journal of Management, 30(4), 498-5 I5. doi: I0. I I 6/j.scaman.20 I 4.05.002

Robert, M., Chiambaretto, P., Mira, B. \& Le Roy, F. (20l8). Better, faster, stronger: The impact of market-oriented coopetition on product commercial performance. M@n@gement, 21 ( ),574-610. Retrieved from https://management-aims.com/index.php/mgmt/article/view/3835

Rouyre, A. \& Fernandez, A.-S. (2019). Managing knowledge sharingprotecting tensions in coupled innovation projects among several competitors. California Management Review, 62(1), 95-120. doi: 10.1177/0008125619885151

Tidström, A. (20/4). Managing tensions in coopetition. Industrial Marketing Management, 43(2), 26 I-27I. doi: I 0. I 0 | 6/j.indmarman.20 I3. $|2.00|$

Vandaie, R. \& Zaheer, A. (20।4). Surviving bear hugs: Firm capability, large partner alliances, and growth. Strategic Management Journal, 35(4), 566-577. doi: 10.1002/smj.21 I5

Wu, Q., Luo, X., Slotegraaf, R. J. \& Aspara, J. (20।5). Sleeping with competitors: The impact of NPD phases on stock market reactions to horizontal collaboration. Journal of the Academy of Marketing Science, 43(4), 490-5 I I. doi: | 0. I007/s I I747-0 |4-0396-3

Yang, H., Zheng, Y. \& Zhao, X. (20I4). Exploration or exploitation? Small firms' alliance strategies with large firms. Strategic Management Journal, 35(I), | 46-I57. doi: I0. I002/smj.2082

\section{Appendices I-2}

